\title{
Comparison of Gaseous Emissions from Stored Biomass Residues
}

\author{
Xiao $\mathrm{He}^{1, *}$, Lianjun Wang ${ }^{1}$, and Anthony Lau ${ }^{2}$ \\ ${ }^{1}$ Jiangsu Key Laboratory of Chemical Pollution Control and Resources Reuse, School of Environmental and Biological \\ Engineering, Nanjing University of Science and Technology, Nanjing, Jiangsu Province, 210094, China \\ ${ }^{2}$ Department of Chemical and Biological Engineering, University of British Columbia, 2360 East Mall, Vancouver, BC, V6T 1Z3, \\ Canada
}

\begin{abstract}
Woody biomass used as alternative fuel to generate power becomes a significant element of sustainability nowadays. Biomass is usually stored for some period before direct combustion or processing in biorefineries. The objective of this study is to quantify and compare the gas emissions from Western Red Cedar (WRC) and Douglas fir (DF) chips during storage at a range of temperatures $\left(5-50^{\circ} \mathrm{C}\right)$ under both non-aerobic and aerobic conditions. Results showed that the dominant mechanism is different depending on the stored materials. Emissions of $\mathrm{CO}$ and $\mathrm{CH}_{4}$ were 2-5 orders of magnitude less than $\mathrm{CO}_{2}$ emission for both WRC and DF chips. The major components of VOCs detected by GC/MS from both materials are similar, consisting of hydrocarbons, aldehyde, terpenes, methanol, acetone, ketone, acid and esters, benzene and its derivatives. The total concentrations of VOC (TVOC) under both conditions differed with temperature, and they were much higher from the DF chips than WRC. The emission factors under the aerobic condition were higher when compared to those under the non-aerobic condition over the storage time period.
\end{abstract}

\section{Introduction}

Renewable resource such as biomass appears to be an attractive feedstock in today's world, due to its sufficiency and lower air pollution when comparing to fossil fuels. Biomass used as clean energy to generate electricity or heat has become an important element of sustainability nowadays [1]. A large amount of biomass in the form of forest residues are harvested annually. The woody biomass is used to produce bioenergy and a full range of biobased products [2].

Generally, it is infeasible to use woody biomass after harvest immediately. The biomass is usually stored in the field for a period before transportation and processing, depending on the production cycles. Moreover, to ensure continuous availability of biomass during the growing season, and guarantee the delivery of chips for heat production during the winter months, it is inevitable to store the biomass materials for extended time period through the supply chain. Growing demand for bioenergy has led to the increasing need for storage of woody materials. The prolonged storage of biomass materials prior to operation will lead to problems. During the holding period, characteristics of biomass may change due to the degradation, thus causing some problems of self- heating, gas emissions and dry matter loss [3,4]. Biomass degrades both chemically and biologically with time. The degradation process leads to heat buildup, which will favor the growth of microbes and generate high temperature in the pile. It may result in self-ignition and spontaneous fires [5]. It has been reported that serious accidents in the past decade were associated to self-heating and fires during biomass storage $[6,7]$.

Gas emission is one of the big problems during the storage since it may affect the surrounding environment and human beings. Gases such as $\mathrm{CO}_{2}, \mathrm{CO}, \mathrm{CH}_{4}$ and VOCs are the main air emission from storage $[3,6,8]$. The assumption about the formation of gas emissions in literature is the biodegradation and oxidation of organic compounds in wood [9]. $\mathrm{CO}_{2}$ is formed from the aerobic or anaerobic biodegradation and thermal oxidation. Wood extractives like fatty acids have been realized as one source of NMVOCs. The breakdown of wood hemicellulose and lignin could result in the emission of NMVOCs as well [10]. The major VOCs from stored wood pellets are known to cause irritation to the respiratory system, namely aldehydes [11]. It is significant to reduce the VOC emissions from woody biomass during storage and then reduce any possible risk to the human beings with optimal production parameters [12].

It is reported the emission rates and the maximum concentrations of the gases reduce at lower temperatures [13]. Tumuluru et al. concluded that the gas emissions from stored wood pellets increased exponentially with

\footnotetext{
* Corresponding author: xhe $@$ njust.edu.cn
} 
storage temperature. When storage temperature was lower than $20^{\circ} \mathrm{C}$, gases increased linearly with respect to storage time [14]. Furthermore, it is found that gas emissions are positively affected by the ambient relative humidity and oxygen availability [15]. In a study of stored wood pellets, the emissions of aldehydes and ketones increased with increment of temperature and $\mathrm{RH}$ (30-90\%) [16].

Few studies have been published on the gas emissions from stored fresh woody biomass. The objectives of this study were to investigate and compare the gas emissions from two types of stored biomass materials (Western Red Cedar and Douglas fir chips) under different temperatures during the storage period. Results will be useful to develop safe storage and transportation of woody biomass.

\section{Materials and methods}

\subsection{Materials}

The materials used in this study were Western Red Cedars (WRC) and Douglas fir (DF) wood chips. WRC chips were obtained from a recycling yard. DF chips were obtained from Fibreco Export Inc. The size of chips was measured by Gilson Testing Screen (TS-1 \& TS-2, Serial No. 2920, Gilson Company, Ohio). The WRC chips had an average size of 10-20 mm while DF ranged from 5-30 $\mathrm{mm}$. Moisture content was measured in triplicate in an oven at $103^{\circ} \mathrm{C}$ for 24 hours according to ASABE Standards S358.2 [17]. The initial moisture content was around $50 \%$ (wet basis). A series of $2 \mathrm{~L}$ glass bottles were used as reactors assembled with valves and sampling ports. Each reactor was loaded with $170 \mathrm{~g}$ dry mass materials.

\subsection{Experimental setup}

Two groups of tests were carried out simulate the infield storage environment, one under aerobic condition and the other under non-aerobic condition. Non-aerobic reactors were sealed to simulate gas emissions under airtight conditions during the storage test. For aerobic condition, air was pumped into the reactors after gas sampling every day so as to refill the oxygen and maintain a high level in the reactors. After loading with the materials, the reactors were sealed and placed under different temperature conditions $\left(5^{\circ} \mathrm{C}\right.$ in a cooler, and in ovens at $20^{\circ} \mathrm{C}, 35^{\circ} \mathrm{C}$ and $50^{\circ} \mathrm{C}$ ). Two replicates were performed for the tests.

\subsection{Gas emission measurement}

The emissions of $\mathrm{CO}_{2}, \mathrm{CO}$ and $\mathrm{O}_{2}$ were measured by gas chromatography (GC Model SRI 8610C, Mandel, USA). The GC was calibrated with the standard gases regularly. The qualitative analysis of the VOCs was analyzed by a GC/MS analyzer (Model 5975B/6890N, Agilent Technologies, USA). During the storage period, gas sample was taken from each reactor to measure the concentrations of $\mathrm{CO}_{2}, \mathrm{CO}$ and $\mathrm{O}_{2}$. The gas was measured every day for the aerobic reactors, whereas the samples from the non-aerobic reactors were analyzed more frequently in the beginning of the test. $250 \mu \mathrm{L}$ gas was taken from each reactor to analyze the VOC composition. The total concentrations of VOCs (TVOC) under aerobic condition were measured by a portable VOC monitor (Model PGM-7240, RAE Systems, San Jose, CA) every day. The same procedure cannot be applied to the reactors under non-aerobic condition since it would lead to a large amount of gas to be released from the reactor and affect the accuracy of analysis for the remaining storage period. Thus, TVOC concentrations from non-aerobic reactors were measured at the end of the test period in order to avoid the release of gases from the containers.

\subsection{Data analysis}

The $\mathrm{CO}_{2}$ emissions are expressed as emission factors, in units of [gram gas species per kilogram dry matter DM) in this study. The measured gas concentration was converted from volumetric percentage to emission factor by using the $\mathrm{N}_{2}$ balance method [18]. At constant temperature and pressure, the emission factor $f$ in $[\mathrm{g} / \mathrm{kg}$ $\mathrm{DM}]$ is associated with volumetric gas concentration $C_{i}$ as follows:

$$
f_{i}=\frac{P\left(C_{i} V\right) M_{w t} C_{n 0}}{R T M C_{n t}}
$$

where $i$ is the gas species, $P$ is the absolute pressure of gas in the reactor $(\mathrm{Pa}), C_{i}$ is volumetric concentration of a particular gas $\left(\mathrm{m}^{3}\right.$ of gas species per $\mathrm{m}^{3}$ of gas going through the GC), $V$ is the gas volume in the reactor $\left(\mathrm{m}^{3}\right)$, $M_{w t}$ is gas molecular weight $(\mathrm{g} / \mathrm{mol}), C_{n 0}$ is the initial concentration of nitrogen $(\%), R$ is universal gas constant $(8.31 \mathrm{~J} / \mathrm{mol} . \mathrm{K}), T$ is temperature $(\mathrm{K}), M$ is the total mass of materials in the reactor $(\mathrm{kg})$ and $C_{n t}$ is the concentration of nitrogen at time $t(\%)$.

\section{Results and discussion}

\subsection{Gas emissions from non-aerobic conditions}

The emission factors of Western Red Cedar (WRC) chips under non-aerobic reactors are shown in Figure 1. It showed that the $\mathrm{CO}_{2}$ emission factor $\left(f_{\mathrm{CO} 2}\right)$ increased gradually for all temperatures as a result of the accumulation of $\mathrm{CO}_{2}$ in the reactors. It is obvious that the emission factors were the highest at $20^{\circ} \mathrm{C}$ followed by $35^{\circ} \mathrm{C}$. However, the emission factors were greatly decreased at $50^{\circ} \mathrm{C}$. The $f_{\mathrm{CO} 2}$ was also low at $5^{\circ} \mathrm{C}$. $f_{\mathrm{CO} 2}$ from the reactor at $20^{\circ} \mathrm{C}$ reached a plateau of $2.8 \mathrm{~g} / \mathrm{kg}$ $\mathrm{DM}$ after around three weeks when the oxygen content depleted to nearly $0 \%$. The value of emission factor corresponds to the $\mathrm{CO}_{2}$ concentration of $16 \%$ (on volumetric basis). The trends of the $\mathrm{O}_{2}$ profiles were exactly opposite to the $\mathrm{CO}_{2}$ profiles at all the temperatures. Lower emission at higher temperature implied that the emission of $\mathrm{CO}_{2}$ might be dominated by biological mechanism rather than chemical mechanism. 
The emission factor of $\mathrm{CO}$ was two orders of magnitude less than $\mathrm{CO}_{2}$.

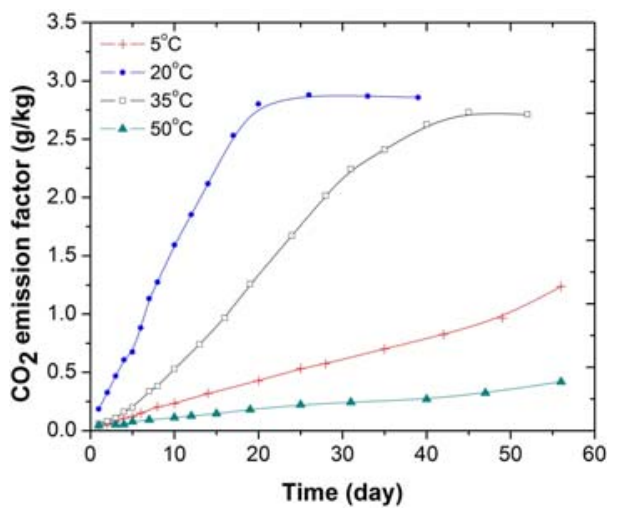

Fig. 1. $\mathrm{CO}_{2}$ emission from stored WRC chips under nonaerobic conditions.

The results of gas emissions from the reactors with Douglas Fir (DF) wood chips under non-aerobic conditions are shown in Figure 2. The emission factors of $\mathrm{CO}_{2}$ increased with time under all temperatures as a result of gas accumulation in the sealed reactors. The value reached a plateau of $2.8-3.0 \mathrm{~g} / \mathrm{kg}$ DM after 10 days storage, which corresponded to a $\mathrm{CO}_{2}$ concentration of $16.5 \%$. Again, the trends of the $\mathrm{O}_{2}$ profiles were opposite to the $\mathrm{CO}_{2}$ profiles at all the temperatures. The emission factor of $\mathrm{CO}_{2}$ increased with temperature implying that the emission from DF chips was likely dominated by chemical mechanism. $\mathrm{CO}$ was found to be four orders of magnitude less than $\mathrm{CO}_{2}$ emission factor. Furthermore, the emissions of $\mathrm{CH}_{4}$ were five orders of magnitude lower than $\mathrm{CO}_{2}$ emission factors.

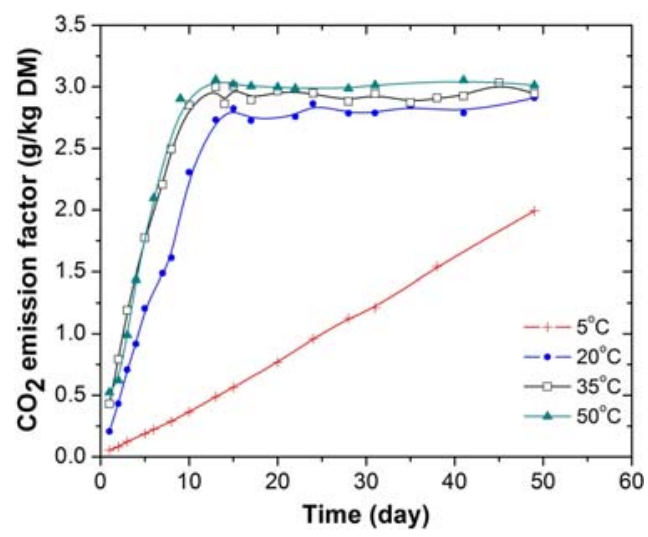

Fig. 2. $\mathrm{CO}_{2}$ emission from stored $\mathrm{DF}$ chips under non-aerobic conditions.

The woody biomass can be decomposed both chemically and biologically. When chemical mechanism is the dominance, the emission will increase with temperature based on the Arrhenius relationship. In addition, temperature plays a key role on biological processes. It can be classified into three cardinal temperatures (minimum, optimum and maximum). The bacteria and fungi would be dormant or even be killed when the temperature is lower or higher than the desired range. From the results, the dominant mechanisms of gas emissions from WRC chips and DF chips are different.
The emissions of $\mathrm{CO}_{2}$ were positively correlated to the temperatures for DF chips, while for WRC chips the highest $\mathrm{CO}_{2}$ emission factor was observed from the reactor at $20^{\circ} \mathrm{C}$. However, the highest emission factors of $\mathrm{CO}_{2}$ from WRC and DF chips were both around $3 \mathrm{~g} / \mathrm{kg}$ $\mathrm{DM}$. The generation of $\mathrm{CO}$ is dominant by chemical reaction and promoted by high temperature. The emissions of $\mathrm{CO}$ from the WRC chips were much higher than those from the DF chips, which might be due to the difference in oxygen levels in the reactors. $\mathrm{CH}_{4}$ emissions were negligible from all the reactors.

The concentrations of VOCs were also analyzed in this study. The major VOCs from both WRC chips and DF chips were similar, including hydrocarbon, aldehydes, methanol, terpene, ketone, acid, esters and aromatic compounds. The total concentrations of VOCs (TVOC) were measured at the end of storage. In both cases, TVOC concentrations increased with temperature. The highest TVOC concentrations were $560 \mathrm{ppm}$ for WRC chips and exceeded $1000 \mathrm{ppm}$ for DF chips. By comparison, TVOC concentrations were approximately 3 times lower from the WRC chips than the DF chips especially at higher temperatures (Table 1).

Table 1. TVOC concentrations (ppm) from all the reactors after storage.

\begin{tabular}{|l|l|l|l|l|l|}
\hline Condition & TVOC conc. & $5^{\circ} \mathrm{C}$ & $20^{\circ} \mathrm{C}$ & $35^{\circ} \mathrm{C}$ & $50^{\circ} \mathrm{C}$ \\
\hline \multirow{2}{*}{$\begin{array}{l}\text { Non- } \\
\text { aerobic }\end{array}$} & WRC chips & 11 & 89 & 237 & 560 \\
\cline { 2 - 6 } Aerobic & DF chips & 12.6 & 256 & 677 & $>1000$ \\
\cline { 2 - 6 } & WRC chips & 20 & 110 & 360 & 800 \\
\cline { 2 - 6 } & DF chips & 11 & 410 & 850 & 9300 \\
\hline
\end{tabular}

\subsection{Gas emissions from aerobic conditions}

The cumulative gas emissions from the stored WRC chips under aerobic reactors are shown in Figure 3. At each temperature, $\mathrm{CO}_{2}$ emissions increased slowly during the storage period. The $\mathrm{O}_{2}$ content kept relatively high and constant as air was pumped into the aerobic reactor every day. Gas emissions from aerobic reactors exhibited similar trends to those from non-aerobic reactors in terms of temperature effect. The highest emission factor of $\mathrm{CO}_{2}$ was observed again from the reactor stored at $20^{\circ} \mathrm{C}$, indicating the biological process might be the dominant force. The total emissions of $\mathrm{CO}_{2}$ ranged from $1-7.5 \mathrm{~g} / \mathrm{kg} \mathrm{DM}$ at different temperatures.

$\mathrm{CO}_{2}$ emission factors $\left(\mathrm{f}_{\mathrm{CO} 2}\right)$ from stored DF chips over the storage period are shown in Figure 4. Higher gas emissions were observed at higher temperatures. The values of $\mathrm{f}_{\mathrm{CO} 2}$ varied from $3 \mathrm{~g} / \mathrm{kg} \mathrm{DM}$ at $5^{\circ} \mathrm{C}$ to $18 \mathrm{~g} / \mathrm{kg}$ $\mathrm{DM}$ at $50^{\circ} \mathrm{C}$. This phenomenon is similar to the anaerobic reactors at the beginning of the test; thus chemical oxidation mechanism could contribute primarily to the emission. The difference between nonaerobic and aerobic conditions became larger afterwards. $\mathrm{CO}$ was observed to be five orders of magnitude lower than the $\mathrm{CO}_{2}$ emission factor from aerobic conditions. 


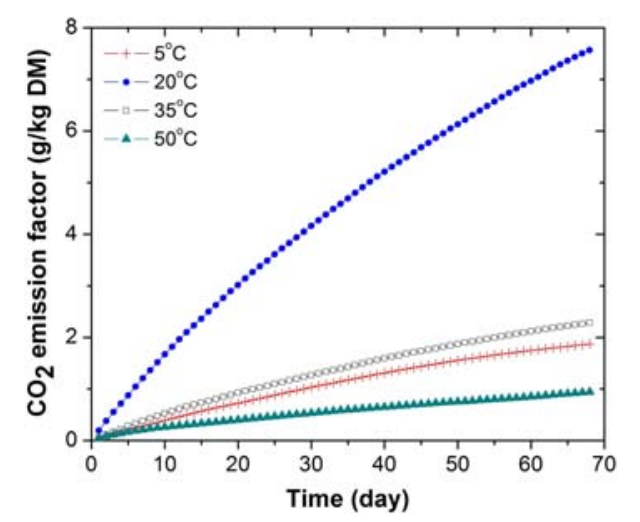

Fig. 3. $\mathrm{CO}_{2}$ emission from WRC chips under aerobic condition.

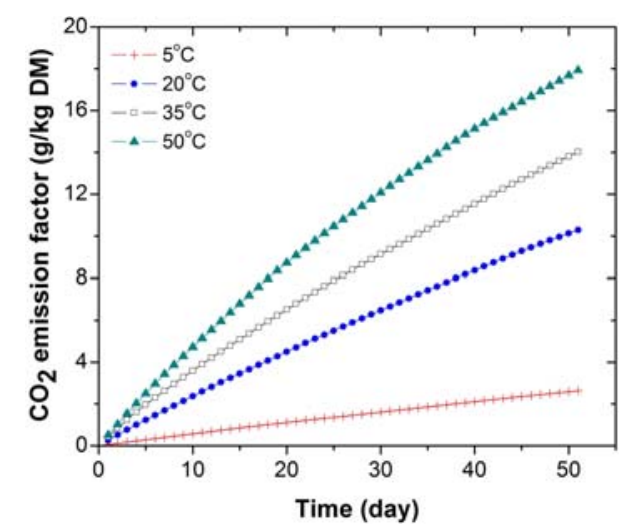

Fig. 4. $\mathrm{CO}_{2}$ emission from DF chips under aerobic condition.

Gas emissions from reactors under aerobic condition displayed the same trends for both WRC and DF materials. The highest emission factor of $\mathrm{CO}_{2}$ for WRC chips was observed to be $6.6 \mathrm{~g} / \mathrm{kg} \mathrm{DM}$ at $20^{\circ} \mathrm{C}$, when comparing to $10.1 \mathrm{~g} / \mathrm{kg} \mathrm{DM}$ for DF chips after 50-day storage. The $\mathrm{f}_{\mathrm{CO} 2}$ of DF chips was $17.7 \mathrm{~g} / \mathrm{kg} \mathrm{DM}$ at $50^{\circ} \mathrm{C}$ at the end of storage. DF chips are more susceptible and degradable as compared to WRC chips with the same initial moisture content under aerobic condition.

As temperature increased, TVOC concentrations of both WRC and DF chips increased. The concentrations of TVOC from WRC chips under aerobic conditions were found to be similar to those under aerobic conditions. The TVOC concentrations from DF chips are almost 10 times higher than those from WRC chips at the beginning, especially under high temperatures. The trends were similar for both WRC and DF chips. TVOC concentrations from DF were much higher than those from WRC chips at the end of the storage, as shown in Table 1. The components of VOCs from WRC chips and DF chips under aerobic condition were similar to those under non-aerobic condition.

\section{Conclusions}

This study demonstrated that gas emissions were measured from woody biomass residues during storage process. Results from the study showed that the correlation between $\mathrm{CO}_{2}$ emissions and temperature varies with the stored biomass and depends on the dominant mechanism. Some common VOCs were observed from both materials. The TVOC concentrations were found to be positively correlated with temperature for both WRC and DF chips under non-aerobic and aerobic conditions. The gas emissions from the reactors under aerobic condition were higher than those from the reactors under non-aerobic condition during the entire storage period. Results revealed that Douglas fir is a more easily degradable biomass than Western Red Cedar.

\section{References}

1. J. Cai, Y. He, X. Yu, S.W. Banks, Y. Yang, X. Zhang, Y. Yu, R. Liu, A.V. Bridgwater. Renew. Sust. Energ. Rev. 76, 14 (2017)

2. C.L. Williams, T.L. Westover, R.M. Emerson, J.S. Tumuluru, C. Li. Bioenergy Res. 9, 14 (2016)

3. L. Eriksson, L. Gustavsson. Biomass Bioenergy 34, 9 (2010)

4. E. Ergul, N. Ayrilmis. Biomass Bioenergy 61, 7 (2014)

5. M. Wihersaari. Biomass Bioenergy 28, 10 (2005)

6. U. Svedberg, C. Petrini, G. Johanson. Ann. Occup. Hyg. 53, 9 (2009)

7. S. Gauthier, H. Grass, M. Lory, T. Kramer, M. Thali, C. Bartsch. Ann. Occup. Hyg. 56, 9 (2012)

8. M. Arshadi, R. Gref. Forest Prod. J. 55, 4 (2005)

9. X. Kuang, T.J. Shankar, S. Sokhansanj, C.J. Lim, X.T. Bi, S. Melin. Ann. Occup. Hyg. 53, 7 (2009)

10. R. Koppmann, K.V. Czapiewski, J. Reid. Atmos. Chem. Phys. Discuss. 5, 61 (2005)

11. K. Hagstrom. Department of Natural Sciences, Orebro University, Doctoral Thesis, (2008)

12. M. Arshadi, P. Geladi, R. Gref, P. Fjallstrom. Ann Occup Hyg. 53, 9 (2009)

13. L. Soto-Garcia, W.J. Ashley, S. Bregg, D. Walier, R. LeBouf, P.K. Hopke, A. Rossner. Energ. Fuel. 29, 9 (2015)

14. J.S. Tumuluru, S. Sokhansanj, C.J. Lim, X.T. Bi, X. Kuang, S. Melin. Int. Wood Prod. J. 4, 10 (2012)

15. E. Alakoski, M. Jamsen, D. Agar, E. Tampio, M. Wihersaari. Renew. Sust. Energ. Rev. 54, 8 (2016)

16. S. Wang, X. Yuan, C. Li, Z. Huang, L. Leng, G. Zeng, H. Li. Fuel 183, 8 (2016)

17. ASABE. American Society of Agricultural Engineers: St. Joseph, MI, USA (2010)

18. X. Kuang, T.J. Shankar, S. Sokhansanj, C.J. Lim, X.T. Bi, S. Melin. Ann. Occup. Hyg. 53, 7 (2009) 